\title{
Combinando Metodologias Ágeis e Ativas no Ensino de Introdução a Programação a Estudantes do Ensino Médio
}

\author{
Bruno N. Moreno ${ }^{1}$ \\ ${ }^{1}$ Campus Nova Cruz - Instituto Federal do Rio Grande do Norte (IFRN) \\ bruno.morenodifrn.edu.br
}

\begin{abstract}
Teaching introductory programming is a challenge regardless the audience of students. For high school students, this challenge could be even greater. Active learning methodologies have been shown as an acceptable approach to teach this topic. It has been observed that these methodologies are very similar to the agile methodologies of software development. This is the point of our discussion: how both approaches can be related to focus on the teaching and learning process of introductory programming to a specific public of students.
\end{abstract}

Resumo. O ensino de introdução a programação é um desafio independentemente do público assistido. Para estudantes do ensino médio, este desafio é ainda maior. As metodologias de aprendizagem ativa têm demonstrado relevantes resultados no ensino deste tópico. Estas metodologias são bastante similares às metodologias ágeis de desenvolvimento de software. Esta é razão do desafio proposto: discutir como essas áreas se relacionam para melhorar o ensino e aprendizagem de introdução a programação para estudantes do ensino médio.

\section{Introdução}

Estudos de diversas áreas têm defendido o ensino de programação na vida escolar. [McCormack and d'Inverno 2012] definem a programação como uma prática criativa. De acordo com [Resnick 2009], por sua vez, o ensino de programação dá suporte ao que se chama de "pensamento computacional" (computational thinking). O pensamento computacional auxilia estudantes a resolver problemas importantes através da elaboração de estratégias que não estão necessariamente relacionadas ao domínio da computação.

O desafio da ensinar programação a adolescentes é sempre presente no IFRN, a instituição em que o autor desta proposta é professor. O IFRN atende, principalmente, estudantes entre 14 e 18 anos do ensino médio. Uma peculiaridade desta instituição é que ela está presente em muitas cidades em situação de vulnerabilidade social, sendo comum, portanto, o atendimento de alunos com diversas deficiências, incluindo aquelas na formação básica, tornando o processo de ensino e aprendizagem ainda mais desafiador.

Diante deste desafio, tem-se buscado formas de ensino de introdução à programação de modo que o estudante tenha melhor proveito no processo de aprendizagem. Neste sentido, as metodologias de aprendizagem ativa [Silberman 1996] vêm sendo aplicadas, no geral, com sucesso. Essas metodologias, no entanto, não foram desenvolvidas focando-se, especificamente, no ensino de tópicos de informática, como programação, por exemplo. De acordo com [Stewart 2009], um limitado número de trabalhos, na verdade, está relacionado à aplicação dessas técnicas no ensino de programação. 
VIII Congresso Brasileiro de Informática na Educação (CBIE 2019)

Anais do VIII Workshop de Desafios da Computação aplicada à Educação (DesafIE 2019)

A discussão proposta é, portanto, avaliar como o ensino e aprendizagem em introdução à programação pode ser otimizado ao convergir as técnicas ativas amplamente discutidas na literatura com aquelas consideradas ágeis da engenharia de software.

\section{Base Teórica}

Na literatura da pedagogia e educação de formação geral tem-se discutido bastante sobre abordagens de aprendizagem ativa. [Bonwell and Eison 1991], por exemplo, sugerem que para aprender, estudantes precisam atuar de forma mais ativa do que simplesmente escutar. [Chickering et al. 1987], do mesmo modo, discutem que além de ler e escrever, estudantes precisam estar envolvidos em questões relacionadas à resolução de problemas. Ao mesmo tempo em que essas abordagens eram desenvolvidas, técnicas e práticas baseadas em princípios e valores do Manifesto Ágil [Beck et al. 2001] passaram a se popularizar na indústria de software. [Stewart 2009] demonstra que métodos ágeis e abordagens de aprendizagem ativa convergem em algumas áreas. Pode-se dizer, por exemplo, que os métodos e técnicas ágeis são ativos tanto quanto as técnicas ativas são ágeis.

De acordo com [Abrahamsson et al. 2003], agilidade é baseada em conceitos como adaptabilidade e flexibilidade. A adaptabilidade e flexibilidade, juntamente com a interatividade e iteratividade - que são conceitos presentes nos métodos ágeis - permitem que o processo de desenvolvimento de um software se dê com o que se chama de "feedback contínuo". Ou seja, através de interações com os clientes do software em produção e seus possíveis usuários, o produto final é adaptado às suas expectativas de forma flexível para todos os envolvidos no processo. Este processo em muito se assemelha com o "aprender fazendo" das metodologias de aprendizagem ativa (learn by doing).

Além de convergir no campo das ideias, é possível observar, também, que as práticas de ambas as áreas são bastante similares. É neste sentido que alguns trabalhos podem ser relacionados. [McBride 2005], por exemplo, aplicou valores do XP (eXtreming Programming) como um modelo para melhoria da didática. [Solingen and Wijnan. 2015] e [Landry and McDaniel 2016], por sua vez, utilizaram Scrum como um framework tanto para o ensino como para o planejamento de um curso completo. Por fim, em [Fontenele and Oliveira 2018] Squad é utilizado para uma ampla remodelagem de uma plataforma de educação utilizada por muitas escolas privadas do país.

Estes são apenas alguns exemplos de como essas áreas podem convergir e como suas técnicas podem ser úteis quando utilizadas em conjunto. Conforme já mencionado, [Stewart 2009] demonstrou que essa compatibilidade existe e que é possível, de fato, mapear os princípios do Manifesto Ágil em um ambiente de sala de aula.

\section{Resultados Esperados}

A proposta a se discutir é: como os princípios, valores, técnicas e processos presentes e incentivados no desenvolvimento ágil podem se relacionar com as metodologias ativas para otimizar o processo de ensino e aprendizagem em disciplinas de introdução a programação com foco, especificamente, em alunos do ensino médio. Como integrar essas metodologias em um processo de meta-aprendizagem focado no ensino de tópicos de programação? Ou seja, como utilizar os conceitos da própria informática (i.e. metodologia ágil) para ensinar de forma ativa sobre introdução a programação? 
Muitas das técnicas ágeis têm similaridades com técnicas de aprendizagem ativa. Para iniciar a discussão, pode-se citar alguns exemplos de convergência: (i) a instrução e a programação por pares são conceitos compatíveis; (ii) o estudo e o trabalho colaborativo são incentivado em ambas metodologias; (iii) a liberdade do estudante em seu aprendizado é semelhante à liberdade das equipes ágeis em sua auto-organização.

O desafio é, portanto, avaliar os caminhos que podem ser seguidos para que ambas metodologias, ágeis e ativas, possam ser utilizadas para otimizar o aprendizado dos alunos no contexto em questão. O objetivo final é definir uma agenda que mostre como essas áreas já se relacionam em termos de seus conceitos e técnicas e definir um mapeamento de convergência para o ensino de introdução a programação no ensino médio considerandose as características do público-alvo já mencionado e incentivando, portanto, a inclusão social e digital, o respeito às múltiplas formas de aprendizado e às diferenças sociais.

\section{Referências}

Abrahamsson, P., Warsta, J., Siponen, M. T., and Ronkainen, J. (2003). New directions on agile methods: A comparative analysis. In Proc. of 25th ICSE, DC, USA.

Beck, K., Beedle, M., van Bennekum, A., Cockburn, A., Cunningham, W., Fowler, M., Grenning, J., Highsmith, J., Hunt, A., Jeffries, R., Kern, J., Marick, B., Martin, R. C., Mellor, S., Schwaber, K., Sutherland, J., and Thomas, D. (2001). Agile manifesto.

Bonwell, C. C. and Eison, J. A. (1991). Active Learning: Creating Excitement in the Classroom. ERIC Clearinghouse on Higher Education Washington, DC.

Chickering, A. W., Gamson, Z. F., and for Higher Education., A. A. (1987). Seven Principles for Good Practice in Undergraduate Education [microform] / Arthur W. Chickering and Zelda F. Gamson. Distributed by ERIC Clearinghouse [Washington, D.C.].

Fontenele, A. and Oliveira, D. (2018). Desafios na potencialização de uma cultura ágil de inovação centrada no usuário: relato de experiência na tecnologia educacional do sas plataforma de educação. In Anais do XVII IHC, Porto Alegre, RS, Brasil. SBC.

Landry, J. P. and McDaniel, R. L. (2016). Agile preparation within a traditional project management course.

McBride, N. K. (2005). A student-driven approach to teaching e-commerc. Journal of Information Systems Education, 16(1):75-84.

McCormack, J. and d'Inverno, M. (2012). Computers and Creativity. Springer.

Resnick, M. e. a. (2009). Scratch: Programming for all. Commun. ACM, 52(11):60-67.

Silberman, M. (1996). Active Learning: 101 Strategies to Teach Any Subject.

Solingen, D. A. R. V. and Wijnan., W. (2015). The eduscrum guide.

Stewart, J. C., e. a. (2009). Evaluating agile principles in active and cooperative learning. In Proceedings of Student-Faculty Research Day, CSIS. 